\title{
Veelplegers en de ISD \\ Een beschrijving van de doelgroep en een eerste verkenning van de werkzaamheid van de ISD
}

\author{
S. Biesma en J. Snippe*
}

De vraag of de ISD-maatregel tot een afname van recidive bij stelselmatige daders leidt, kan slechts worden beantwoord door een effectevaluatie van de maatregel. Deze zal naar verwachting vanaf 2009 plaatsvinden. Tot de effecten van de ISD-maatregel bekend zijn, kunnen we een meer of minder onderbouwde inschatting geven van de werkzaamheid. De afgelopen jaren heeft onderzoeksbureau INTRAVAL diverse onderzoeken verricht naar veelplegers, onder meer naar de Strafrechtelijke Opvang Verslaafden (SOV), de voorloper van de maatregel Inrichting voor Stelselmatige Daders (ISD). Bovendien hebben wij een vergelijking gemaakt tussen beide maatregelen. Daarbij stond het achterhalen van de meerwaarde van de ISD-maatregel ten opzichte van de SOV centraal. Verder heeft INTRAVAL assistentie verleend aan de Inspectie voor de Sanctietoepassing (ISt) bij haar thema-onderzoek ISD. Daarnaast is de doelgroep van de ISD een terugkerend onderwerp van onze onderzoeken. In dit artikel zullen we een beschrijving geven van deze doelgroep, waarbij naast enkele kenmerken van veelplegers ook hun recidive de aandacht krijgt. Dit gebeurt aan de hand van de onderzoeksgegevens van de regio Twente voor de jaren 2004-2006. Vervolgens wordt aangegeven welk type gedetineerden binnen de SOV en ISD zijn aangetroffen, hoe de ISD is vormgegeven en wat de meerwaarde van de ISD-maatregel is ten opzichte van de SOV. Afgesloten wordt met enkele bevindingen over de doelgroep die met de ISD-maatregel wordt bereikt en de invulling van de maatregel in de praktijk.

* Sasja Biesma (psycholoog) en Jacco Snippe (sociaal geograaf) zijn werkzaam als onderzoeker bij onderzoeks- en adviesbureau INTRAVAL uit Groningen. 


\section{Veelplegers}

Bij diverse organisaties is het thema reelplegers één van de speerpunten van beleid. Ook in het kader van het zogenoemde Grotestedenbeleid (GSB) is er veel aandacht voor veelplegers. $\mathrm{Zij}$ worden verantwoordelijk gehouden voor een onevenredig groot deel van de diefstallen en inbraken. Door het aanpakken van de veelplegers is de verwachting dat de criminaliteit in de grote steden zal dalen. Voor een goede beleidsvorming en -uitvoering is inzicht in de samenstelling van categorieën veelplegers van belang. Landelijk volgt het WODC van het ministerie van justitie de veelplegers. In deze monitor worden enkele keren per jaar de informatie over jeugdige en volwassen zeer actieve veelplegers, hun criminaliteit en de reactie van politie en justitie in kaart gebracht. De meest recente gegevens hebben betrekking op 2006. ${ }^{1}$ In de regio Twente heeft de regiegroep veelplegers casu quo het Arrondissementaal Juridisch Beraad (AJB) aan INTRAVAL gevraagd de veelplegers te monitoren en tactische casu quo strategische informatie te geven over de aard en omvang van de door veelplegers gepleegde criminaliteit en hun detentieverleden. Deze informatie diende te worden uitgesplitst naar vier doelgroepen: zeer actieve meerderjarige veelplegers, actieve meerderjarige veelplegers, jeugdige meerplegers en jeugdige veelplegers. Dit onderzoek is gestart in 2005 met het cohort veelplegers van 2004. Momenteel zijn daar de cohorten 2005 en 2006 aan toegevoegd, terwijl de resultaten van het cohort 2007 met het AJB is besproken maar nog niet openbaar zijn gemaakt.

\section{Definities}

De aanduiding voor 'veelpleger' wordt bepaald aan de hand van landelijke definities. De gehanteerde definities voor (zeer actieve) veelplegers zijn:

Veelpleger: een persoon van 18 jaar of ouder die in zijn/haar gehele criminele carrière meer dan tien processen-verbaal heeft gekregen, waarvan tenminste één in het peiljaar.

1 N. Tollenaar, e.a.: Jeugdige en zeer actieve volwassen veelplegers in kaart gebracht, Den Haag: Boom Juridische Uitgevers 2008. 
Zeer actieve veelpleger: een persoon van 18 jaar of ouder die over een periode van vijf jaar (waarvan het peiljaar het laatste jaar is) meer dan tien processen-verbaal heeft ontvangen, waarvan tenminste één in het peiljaar.

Stelselmatige daders: zeer actieve veelplegers die in de vijf jaren voorafgaand aan het gepleegde feit tenminste drie maal wegens het plegen van een misdrijf onherroepelijk zijn veroordeeld tot een vrijheidsbenemende of vrijheidsbeperkende straf of maatregel en die ook ten uitvoer moet zijn gelegd.

Meerpleger: iemand van 18 jaar of ouder die in het gehele criminele verleden minder dan tien en meer dan twee processen-verbaal tegen zich zag opgemaakt, waarvan tenminste één in het peiljaar.

Voor de beschrijving van de ontwikkelingen binnen een cohort wordt gebruik gemaakt van de termen die het WODC in haar monitor veelplegers hanteert. Hieronder worden de definities van deze termen weergegeven. $^{2}$

Aanhouder: een (zeer actieve) veelpleger of jeugdige meer- of veelpleger uit een cohort die één of meerdere nieuwe antecedenten (processenverbaal) heeft in één van de volgende jaren en daarmee nog steeds of wederom tot de (zeer actieve) veelplegers of jeugdige meer- of veelplegers behoort.

Stilhouder: een (zeer actieve) veelpleger of jeugdige meer- of veelpleger uit een cohort die geen nieuwe antecedenten heeft in één van de volgende jaren bij de regiopolitie Twente en dus geen (zeer actieve) veelpleger of jeugdige meer- of veelpleger meer is.

\section{Veelplegers in Twente}

De regiopolitie Twente stelt evenals andere politiekorpsen jaarlijks een lijst van veelplegers op, met gebruikmaking van de landelijke definities. Deze veelplegerlijsten worden aan de onderzoekers verstrekt. Zij vullen deze lijsten aan met gegevens over antecedenten, veroordelingen, detenties en bekendheid bij de hulpverlening. Deze informatie is momenteel be-

2 N. Tollenaar, e.a. WODC-recidivestudie Fact sheet 2006-12. Monitor veelplegers. Samenvatting van de resultaten. Den Haag: WODC 2006. 
schikbaar voor de jaren 2004, 2005 en 2006. De op de veelplegerlijst voorkomende personen worden in de tijd gevolgd. In dit zogenoemde cohortonderzoek worden de (zeer actieve) veelplegers en jeugdige meeren veelplegers over een langere periode met tijdsintervallen van een jaar onderzocht op hun antecedenten en overige justitiecontacten (veroordeling, detentie, reclassering). ${ }^{3}$

\section{Omvang (zeer actieve) veelplegers}

In totaal staan in 2004843 personen op de Twentse lijst: 676 veelplegers en 167 zeer actieve veelplegers (tabel 1). In 2005 gaat het in totaal om 859 personen waarvan 690 tot de categorie veelpleger behoren en 169 tot de categorie zeer actieve veelpleger. Op de lijst van 2006 staan in totaal 863 personen: 710 veelplegers en 153 zeer actieve veelplegers.

\begin{tabular}{l|l|l|l}
\multicolumn{2}{c}{ Tabel 1 } & \multicolumn{3}{l}{ Aantallen (zeer actieve) veelplegers per cohort } \\
\hline \hline & $\begin{array}{l}\text { Zeer actieve } \\
\text { veelplegers }\end{array}$ & Veelplegers & Totaal \\
\hline 2004 & 167 & 676 & 843 \\
\hline 2005 & 169 & 690 & 859 \\
\hline 2006 & 153 & 710 & 863 \\
\hline \hline
\end{tabular}

De belangrijkste ontwikkelingen die zich in de periode 2004-2006 onder de (zeer actieve) veelplegers in de regio Twente hebben voorgedaan, zijn de volgende:

\section{Ontwikkelingen}

Het aantal zeer actieve veelplegers is licht gedaald (van 167 in 2004 naar 153 in 2006), terwijl het aantal veelplegers is gestegen (van 676 in 2004 tot 710 in 2006). Bij verdachten onder de 18 jaar is het aantal veelplegers nagenoeg constant gebleven en is het aantal meerplegers gestegen.

Jaarlijks stroomt ruim de helft van de volwassen veelplegers als een zogenoemde stilhouder uit een cohort. Dit betekent dat deze veelplegers niet langer bij de politie voor het plegen van een misdrijf zijn geregistreerd.

3 A. Kruize, J. Snippe, M. van Zwieten, B. Bieleman: Monitor 2007. Veelplegers Twente, Groningen-Rotterdam: St. INTRAVAL 2008. 
Cohorten (zeer actieve) veelplegers

Van de cohorten veelplegers is rond de $60 \%$ één en twee jaar later een stilhouder. Dit betekent dat meer dan de helft van de volwassen veelplegers een jaar later niet in de politieregistratie voorkomt. Krijgt hij het volgende jaar wel weer een proces-verbaal voor het plegen van een misdrijf dan komt hij weer als veelpleger op de lijst (tabel 2). De meest actieve periode in de criminele carrière van persoon 1 uit deze tabel is inmiddels achter de rug, maar hij zal bij elk misdrijf waarvoor hij een proces-verbaal ontvangt tot in lengte van dagen op de veelplegerlijst terugkeren. Ook persoon 2 voldoet aan het profiel van een veelpleger. Het verschil met persoon 1 is dat zijn criminele carrière gelijkmatiger verloopt. Met één of twee processen-verbaal per jaar wordt hij geen zeer actieve veelpleger, wel zal ook hij regelmatig op de veelplegerlijst komen te staan. De term veelpleger suggereert een actieve crimineel die stelselmatig misdrijven pleegt. In de praktijk staan er relatief veel personen op veelplegerslijsten die gedurende meerdere jaren ten hoogste eenmaal per jaar een proces-verbaal voor het plegen van een misdrijf krijgen.

De criminele carrière van veelplegers is vaak lang. Gemiddeld ontvangen zij hun eerste proces-verbaal op de leeftijd van 17 jaar. De gemiddelde leeftijd ligt al jarenlang op ongeveer 38 jaar, bij een leeftijd die varieert van 19 tot 76 jaar. Minder dan $10 \%$ is echter jonger dan 25 jaar, ongeveer $15 \%$ is ouder dan 50 jaar. Twee derde van de (zeer actieve) veelplegers is tussen de 30 en de 50 jaar. Het potentieel aan veelplegers in een regio is relatief groot. Jaarlijks zien we een relatief grote instroom van veelplegers die het jaar daarvoor of gedurende enkele jaren niet in de registratie voorkwamen en tijdelijk stilhouder zijn geweest. Van de stilhouders keert een jaar later de helft als veelpleger terug in de registratie. Niet uitgesloten is uiteraard dat een stilhouder wel een misdrijf heeft gepleegd, maar hiervoor door de politie niet is aangehouden en geverbaliseerd. Ook kan het zijn dat hij in een andere politieregio een misdrijf heeft gepleegd. 
Tabel 2 Fictief voorbeeld registratie-effecten (zeer actieve) veelpleger

\begin{tabular}{|c|c|c|c|c|c|c|c|c|}
\hline & 1999 & 2000 & 2001 & 2002 & 2003 & 2004 & 2005 & 2006 \\
\hline \multicolumn{9}{|l|}{ Persoon 1} \\
\hline $\begin{array}{l}\text { processen- } \\
\text { verbaal }\end{array}$ & 5 & 3 & 3 & 1 & 1 & 0 & 1 & 1 \\
\hline veelpleger & nee & nee & nee & ja & ja & nee & ja & ja \\
\hline $\begin{array}{l}\text { zeer actieve } \\
\text { veelpleger }\end{array}$ & nee & nee & nee & ja & nee & nee & nee & nee \\
\hline \multicolumn{9}{|l|}{ Persoon 2} \\
\hline $\begin{array}{l}\text { processen- } \\
\text { verbaal }\end{array}$ & 2 & 2 & 2 & 2 & 2 & 1 & 1 & 0 \\
\hline veelpleger & nee & nee & nee & nee & nee & nee & ja & nee \\
\hline $\begin{array}{l}\text { zeer actieve } \\
\text { veelpleger }\end{array}$ & nee & nee & nee & nee & nee & nee & nee & nee \\
\hline
\end{tabular}

\section{Misdrijven}

Zowel veelplegers als zeer actieve veelplegers zijn in het Herkenningsysteem (HKS) van de politie vooral geregistreerd voor vermogensdelicten. In de periode $2004-2007$ is ongeveer zes tiende (56\%-60\%) van de door veelplegers gepleegde misdrijven een vermogensdelict, tegenover twee derde (64\%-70\%) bij de zeer actieve veelplegers (tabel 3). Een aanzienlijk lager percentage (rond de $15 \%$ ) betreft geweldsdelicten. Bij de zeer actieve veelplegers is dit nog enigszins lager (10-12\%). De overige misdrijven (rond een kwart) zijn met name vernielingen, verkeersmisdrijven en overtredingen van de Opiumwet.

Verder blijkt uit tabel 3 dat het totale aantal door veelplegers gepleegde misdrijven in de jaren is toegenomen van 26.964 tot 28.461, een stijging van $5,6 \%$. In dezelfde periode is het totale aantal door zeer actieve veelplegers gepleegd misdrijven afgenomen van 12.113 tot 11.343 , een daling van $6,4 \%$. 
Tabel 3 Totaal aantal geregistreerde misdrijven (zeer actieve) veelplegers Twente in 2004-2006

\begin{tabular}{l|l|l|l|l|l|l}
\cline { 2 - 7 } & \multicolumn{4}{c|}{ Veelplegers } & \multicolumn{3}{|l}{ Zeer actieve veelplegers } \\
\cline { 2 - 7 } & 2004 & 2005 & 2006 & 2004 & 2005 & 2006 \\
\hline \hline Geweld & 3.669 & 4.160 & 3.736 & 1.397 & 1.538 & 1.243 \\
\hline Vermogen & 16.961 & 17.506 & 16.336 & 8.016 & 8.709 & 7.593 \\
\hline Vernieling & 1.501 & 2.950 & 3.456 & 1.299 & 1.286 & 1.207 \\
\hline Opium & 765 & 794 & 787 & 191 & 238 & 213 \\
\hline Verkeer & 2.509 & 2.735 & 2.778 & 808 & 708 & 598 \\
\hline Overig & 1.559 & 1.228 & 1.368 & 402 & 424 & 488 \\
\hline Totaal & 26.964 & 29.373 & 28.461 & 12.113 & 12.903 & 11.342 \\
\hline
\end{tabular}

\section{Detentie}

Het merendeel van de veelplegers (rond de 60\%) blijkt in het afgelopen jaar niet te zijn gedetineerd. Ongeveer $40 \%$ heeft wel in detentie gezeten. Van de stilhouders heeft in het jaar dat zij niet in de registratie van de politie voorkomen ongeveer een vijfde tot een kwart (een gedeelte van het jaar) in detentie gezeten, hetgeen deels een verklaring is voor hun stilhouderschap.

Rond de $40 \%$ van de veelplegers is aanhouder en blijft derhalve terugkomen in de politieregistratie. De meesten zijn ook een jaar later nog veelpleger, een minderheid is doorgegroeid naar de categorie van zeer actieve veelpleger. Van de aanhouders is de overgrote meerderheid (83\% tot $91 \%$ ) in het jaar van aanhouding veroordeeld, ruim de helft (54\% tot $60 \%$ ) heeft in de loop van het jaar in detentie gezeten.

Zeer actieve veelplegers volharden meer in crimineel gedrag dan veelplegers. Het percentage stilhouders is in de cohorten zeer actieve veelplegers lager dan onder de veelplegers: $21 \%$ tot $37 \%$ is stilhouder. Van deze stilhouders heeft wel een deel in detentie gezeten. De jaarlijkse percentages lopen sterk uiteen, van een kwart (26\%) tot $61 \%$.

Van de zeer actieve veelplegers is een ruime meerderheid $(63 \%$ tot $79 \%$ ) aanhouder. Nagenoeg alle aanhouders zijn veroordeeld tot uiteenlopende sancties $(89 \%$ tot $95 \%$ ), een iets lager percentage $(77 \%$ tot $91 \%)$ is gedetineerd geweest. 


\section{ISD}

De op 1 april 2001 in werking getreden Wet SOV ${ }^{4}$ introduceerde een voorziening voor de strafrechtelijke opvang van justitiabele verslaafden in een speciale penitentiaire inrichting. Het ging om een maatregel die op vordering van het Openbaar Ministerie (OM) door de strafrechter kon worden opgelegd. De maatregel gold voor een maximale duur van twee jaar. ${ }^{5} \mathrm{Bij}$ deze maatregel hoefde geen rechtstreeks verband te bestaan tussen de ernst van de gepleegde feiten en de zwaarte van de (strafrechtelijke) reactie daarop, wel tussen de frequentie van recidive en de zwaarte van de reactie. In 2004 is de SOV opgegaan in de ISDmaatregel. ${ }^{6}$ Het SOV-programma is geïntegreerd in de ISD en vormt nu één van de programma's binnen de ISD. ${ }^{7}$ Ook de ISD-maatregel maakt het mogelijk een zeer actieve veelpleger voor maximaal twee jaar in een daarvoor aangewezen inrichting te plaatsen. De ISD-maatregel is evenwel breder dan de eerdere SOV: in principe kunnen alle zeer actieve veelplegers een ISD-maatregel opgelegd krijgen, mits ook wordt voldaan aan de voorwaarden voor een stelselmatige dader. Drugsverslaving, een psychiatrische stoornis of geslacht zijn geen contra-indicaties voor oplegging van de maatregel ISD. Deze aspecten vormden bij de eerdere SOV wel een contra-indicatie. De wet staat niet toe dat de ISDmaatregel wordt opgelegd aan degene aan wie het feit geheel niet is toe te reken.

\section{Doelgroep}

De wettelijke doelgroep van de ISD-maatregel is groter dan die van de SOV, omdat er afgezien van ontoerekeningsvatbaarheid geen contraindicaties gelden en derhalve ook niet-verslaafden, vrouwen en justitiabelen met een psychiatrische problematiek tot een ISD-maatregel kunnen worden veroordeeld. Deze wettelijke verbreding van de doelgroep van 'verslaafd' naar 'verslaafd, en niet verslaafd, al dan niet met psychische problemen' maakt de uitvoering van de maatregel niet eenvoudiger.

4 Wet van 21 december 2000, Stb 2001, 28.

5 Besluit van 27 maart 2001 tot wijziging van de Penitentiaire maatregel met betrekking tot de strafrechtelijke opvang verslaafden, Stb 2001, 159.

6 Wet van 9 juli 2004, Stb 2004, 351.

7 Hier wordt gesproken over de eerdere SOV-maatregel. Binnen de ISD kan er sprake zijn van een SOV-traject. Dit laatste wordt het huidige SOV-traject genoemd. 
Ongeveer twee derde van de meerderjarige zeer actieve veelplegers zou verslaafd zijn aan harddrugs. ${ }^{8}$ De niet-verslaafde veelpleger heeft een ander profiel dan de verslaafde veelpleger. De niet-verslaafde veelpleger pleegt niet alleen veel verschillende vormen van vermogensdelicten, maar zou zich ook bezighouden met een breder scala aan misdrijven. ${ }^{9}$ Hij heeft minder feiten per keer in zijn strafdossier en wordt ook minder vaak aangehouden. Hij woont vaker samen of heeft een gezin, heeft vaker werk en is vaker van Nederlandse afkomst. Bij niet-verslaafde veelplegers is er soms sprake van psychische problematiek of deze veelplegers zijn om andere redenen de greep op hun leven kwijt geraakt. Dit kan zich bijvoorbeeld uiten in financiële problemen (schulden). Ook verslaafde veelplegers hebben overigens vaak schulden. Met name de relatief veel voorkomende hoge bedragen aan niet betaalde boetes kunnen een knelpunt zijn bij het bieden van schuldhulpverlening.

\section{SOV en ISD vergeleken}

Ten behoeve van de vergelijking van de eerdere SOV en de ISDmaatregel is een aantal kenmerken van ISD-ers op basis van RIScgegevens ${ }^{10}$ uitgezocht. ${ }^{11}$ Het betreft hier RISc-gegevens van de gehele ISD-populatie ten tijde van het onderzoek (medio 2006). Daarnaast zijn destijds op vier ISD-locaties waar voorheen ook een SOV-inrichting

8 In 'Bekentenissen, veelplegers over hun dagelijkse praktijk', 2005, een onderzoek van de regiopolitie Amsterdam-Amstelland onder veelplegers blijken overigens vier op de tien (37\%) jeugdige en volwassen veelplegers in het HKS als harddrugsgebruikers te zijn geregistreerd. Het werkelijke percentage drugsverslaafden onder veelplegers zal hoger zijn, met name onder de meest actieve categorie. Bekend is bovendien dat niet alle drugsverslaafden de gevarenclassificatic 2 (harddrugsgebruiker) ontvangen, met name jeugdige gebruikers niet. Verslaafde veelplegers blijken in dit onderzoek verder veel vermogensdelicten te plegen, maar ook opvallend veel geweldsdelicten (openlijke geweldpleging, overvallen, bedreiging en mishandeling).

9 B.S.J. Wartna, N. Tollenaar. Bekenden van Justitie: Een verkennend onderzoek naar de 'veelplegers' in de populatie van vervolgde daders. Den Haag: Boom Juridische Uitgevers / WODC, 2004.

10 Risico Inschatting Schalen: een diagnostisch instrument van reclassering en gevangeniswezen voor het inschatten van de kans op recidive.

11 S. Biesma, M. van Zwieten, J. Snippe, B. Bieleman, ISD en SOV vergeleken. Eerste inventarisatie meerwaarde Inrichting voor Stelselmatige Daders boven eerdere Strafrechtelijke Opvang Verslaafden, Groningen-Rotterdam: St. INTRAVAL 2006. 
was gevestigd (Amsterdam, Utrecht, Vught en Zoetermeer), gesprekken gevoerd met betrokkenen bij de uitvoering van de ISD-maatregel.

Uit de bestudeerde documenten en de gesprekken met de beleidsopstellers is gebleken dat zowel de maatregel ISD als de eerdere SOV moeten leiden tot het terugdringen van recidive. De belangrijkste (dubbele) doelstelling van zowel de eerdere SOV als de ISD-maatregel is het realiseren van een gedragsverandering door het doorbreken van de vicieuze cirkel van opsluiten - vrijlaten - delicten plegen - veroordelen opsluiten. De criminele recidive moet worden teruggedrongen door de resultaten van de interventies te vergroten, waarvoor een beter aanbod van gedragsbeïnvloedende programma's op maat en toezicht worden ontwikkeld. De langere detentieperiodes, het verminderen van de met het delictgedrag samenhangende (verslavings)problematiek en het aanbieden van nazorg na detentie spelen hierbij een belangrijke rol. De veronderstelling is dat er met de verbreding van de doelgroep en een stringentere controle op de naleving van landelijke kaders, meer zeer actieve veelplegers bereikt en geholpen worden. Uiteindelijk zou minder recidive van ISD-deelnemers en daarmee een reductie van de criminaliteit, met name de vermogensmisdrijven, het maatschappelijke resultaat moeten zijn.

Voor oplegging van de SOV of de ISD-maatregel is de instemming of bereidheidverklaring van de verdachte niet vereist. De toewijzing gebeurt met andere woorden onder dwang. Het vervolgens al dan niet deelnemen aan het programma is in principe wel vrijwillig, maar er vindt een zekere mate van drang plaats om een intrinsieke motivatie bij de betrokken justitiabele te bewerkstelligen. Het aanbod - binnen de eerdere SOV verspreid over drie fasen, binnen de ISD over twee fasen dient vervolgens te leiden tot gedragsveranderingen ofwel het verminderen van de criminogene factoren. Binnen de ISD wordt, meer dan bij de eerdere SOV, specifiek aandacht besteed aan de motivatie van de justitiabele. De eerdere SOV had meer aandacht voor verslaving als criminogene factor, hoewel de aanvankelijke gerichtheid op abstinentie na verloop van tijd is losgelaten. 


\section{Meerwaarde}

De beoogde meerwaarde van de ISD ten opzichte van de eerdere SOV kan als volgt worden samengevat:

- Instroom: meer veroordeelden.

- Doelgroep: bredere groep veroordeelden en systematischere screeningveroordeelden.

- Aanbod van interventies in ISD: grotere deelname aan het programma casu quo aan de interventies, tevens een flexibeler aanbod.

- Organisatie: sterkere (koppeling) strafrechtelijke en hulpverleningsketen en betere ketensamenwerking.

Belangrijke verschillen tussen de eerdere SOV en de maatregel ISD zijn volgens zowel de geïnterviewde beleidsopstellers als de beleidsnotities: de bredere doelgroep van de ISD-maatregel (ook niet-drugsverslaafden, vrouwen en personen met een psychiatrische problematiek), de grotere detentiecapaciteit, de screening met de RISc voor het bepalen van criminogene factoren, een flexibel aanbod van gedragsbeïnvloedende interventies gericht op het wegnemen van criminogene factoren en de betere naleving van landelijke kaders voor ketensamenwerking bij de instroom (casusoverleg).

In de praktijk blijkt de veronderstelde meerwaarde zich soms wel en soms niet voor te doen. Wat betreft de instroom blijkt dat het absolute aantal veroordeelden inderdaad groter is bij de ISD-maatregel. De bezettingsgraad bij de ISD is daarentegen na bijna twee jaar lager dan na eenzelfde periode bij de eerdere SOV. Wettelijk is de doelgroep bij de ISD-maatregel breder geworden: ook vrouwen en personen met een psychiatrische problematiek krijgen de maatregel opgelegd. De beoogde uitbreiding naar niet-verslaafde justitiabelen is echter nog nauwelijks gerealiseerd. In tegenstelling tot de eerdere SOV worden de ISD veroordeelden met behulp van de RISc systematisch gescreend. Ten aanzien van het aanbod worden in de ISD knelpunten ervaren in de aansluiting tussen de intramurale en de extramurale fase (met name de moeizame instroom en verblijf in vervolgvoorzieningen), de omgang met de psychiatrische problematiek van veroordeelden, het feitelijke aanbod van interventies in de Penitentiaire Inrichting en de beperkte capaciteiten van de veroordeelden. Dit neemt niet weg dat het aanbod wel als flexibeler wordt ervaren door medewerkers van justitie. Voor wat betreft 
de organisatie wordt de beoogde sterkere (koppeling van) strafrechtelijke en hulpverleningsketen in de praktijk daadwerkelijk ervaren, evenals een betere ketensamenwerking. Het systeem van de zogenoemde duale momenten, de samenwerking en afstemming tussen strafrechtelijk en hulpverleningsketen, wordt echter niet door iedereen gewaardeerd.

\section{Bevindingen Inspectie voor de Sanctietoepassing}

De Inspectie voor de Sanctietoepassing, kortweg Inspectie, heeft op zes ISD-locaties onderzocht of de betrokken penitentiaire inrichtingen en reclasseringsinstellingen bij de tenuitvoerlegging van de maatregel doen wat van hen mag worden verwacht. ${ }^{12}$ De ISD-maatregel is destijds ingevoerd met de nadruk op de beveiliging van de maatschappij door middel van langdurige opsluiting van veelplegers. De Inspectie stelt echter vast dat gaandeweg, mede onder invloed van rechterlijke beslissingen, de inhoud van de ISD maatregel bijna altijd ook een resocialisatietraject bevat. Dat heeft gevolgen voor de uitvoering. Enerzijds constateert de Inspectie dat enthousiaste en betrokken medewerkers op zoek zijn naar creatieve oplossingen om het resocialisatietraject vorm te geven. Anderzijds heeft de Inspectie ook moeten vaststellen dat er in een flink aantal opzichten verbeteringen nodig zijn.

Het Inspectieonderzoek beoogt vast te stellen of de betrokken penitentiaire inrichtingen en reclasseringsinstellingen bij de tenuitvoerlegging van de ISD-maatregel doen wat van hen mag worden verwacht. De resultaten wijzen er op dat die tenuitvoerlegging in veel opzichten moet worden verbeterd. Op een aantal problemen kon moeilijk worden geanticipeerd. Deze zijn pas in de loop van de implementatie aan het licht gekomen. Zo bleken veel meer ISD-ers dan verwacht te kampen met ernstige psychiatrische problemen, al dan niet in combinatie met een verstandelijke handicap. De juiste opvang van deze categorie stelt bijzondere eisen, ook aan zorginstellingen die de opvang van deze ISDers in de extramurale fase van de maatregel voor hun rekening nemen. Daar komt bij dat de rechterlijke macht bij de oplegging van de maatregel veel meer is uitgegaan van het oude SOV-principe 'behandeling,

12 Inspectie voor de Sanctietoepassing, Inrichtingen voor Stelselmatige Daders. Inspectierapport Themaonderzoek, Den Haag: Ministerie van Justitie 2008. 
tenzij' dan van de bij de invoering van de ISD-maatregel voorliggende oriëntatie op directe maatschappijbeveiliging. De aanvankelijke verwachting bij beleidsmakers dat bij de ISD-maatregel meestal sprake zou zijn van sobere detentie, is niet uitgekomen. Hieronder worden de bevindingen van de Inspectie kort samengevat.

\section{Voorfase en instroom}

In de grotere gemeenten in de ISD-regio's wordt in kaart gebracht welke veelplegers bij een eerstvolgende aanhouding in aanmerking komen voor de ISD-maatregel. Als een ISD-kandidaat eenmaal is aangehouden, dan wordt de (verslavings)reclassering gevraagd een voorlichtingsrapportage op te stellen. Om de criminogene problemen op de verschillende leefgebieden vast te stellen wordt de RISc afgenomen. Over het algemeen verloopt de advisering aan de rechterlijke macht door de reclassering naar tevredenheid. In een enkel geval is het voorlichtingsrapport echter niet tijdig beschikbaar en moet worden afgezien van het vorderen en opleggen van de ISD-maatregel. Verder kan het ontbreken van een gedragskundig rapport ertoe leiden dat de ISD-maatregel wordt opgelegd aan veelplegers die daarvoor - naar achteraf blijkt - ongeschikt zijn.

\section{Verblijfsplan}

In de Penitentiaire beginselenwet is voorgeschreven dat voor iedere ISD-er binnen een maand na binnenkomst een verblijfsplan wordt opgesteld. In de praktijk lukt dit lang niet altijd. De inhoudelijke opzet van de verblijfsplannen verschilt van locatie tot locatie. De Inspectie heeft verder gesignaleerd dat een aantal inrichtingen een speciale assessment- of trajectpsycholoog heeft aangetrokken om te adviseren over het wenselijke ISD-traject als er sprake is van psychische of verstandelijke problemen.

\section{Intramurale fase}

De wet staat toe dat de tenuitvoerlegging van de eerste fase van de ISDmaatregel zowel in een regime van algehele gemeenschap als van beperkte gemeenschap plaats kan vinden. Beide varianten komen in de praktijk voor. Ook in andere opzichten verschilt de regimeopzet tussen de ISD-locaties sterk. Sommige regimes bieden ook ruimere mogelijkheden om een reïntegratietraject te ondersteunen dan andere. Onderdeel van de verblijfsplannen zijn gedragsinterventies. Vaak zijn dit trainingen die door reclasseringsorganisaties worden verzorgd. De realisatie 
van de in de verblijfsplannen opgenomen gedragsinterventies blijft in veel ISD-locaties achter. Daarnaast komt het voor dat ISD-ers aan een training deelnemen die niet in het verblijfsplan is geïndiceerd, bijvoorbeeld om de deelnemersgroep voor die training te completeren. Als bijzonder probleem wordt door de Inspectie het beperkte programmatische aanbod voor ernstig psychisch gestoorde gedetineerden of ISD-ers met zeer beperkte verstandelijke vermogens gezien. Om ISD-ers te motiveren deel te nemen aan een reïntegratietraject en hen daarbij te begeleiden, zijn trajectbegeleiders werkzaam. Eén van de bevindingen van de Inspectie is dat deze trajectbegeleiders niet aan de landelijk voorgeschreven richtlijn voldoen om ISD-ers wekelijks te spreken.

Hoewel het algemene bejegeningsklimaat in de ISD-locaties als correct wordt beoordeeld door de Inspectie, blijkt dat vooral op afdelingen waar naast ISD-ers ook andere gedetineerden verblijven het afdelingsklimaat het gedragsveranderingstraject onvoldoende ondersteunt. Verder is het van belang dat alle ISD-ers een mentor krijgen. Dat is nu nog niet overal het geval. De Inspectie heeft ook vastgesteld dat binnen de mogelijkheden die het gevangeniswezen daartoe biedt, de ISD-ers over het algemeen voldoende toegang hebben tot psychomedische zorg. Nagenoeg alle partijen waarmee de Inspectie heeft gesproken pleiten voor herinvoering van de halfopen fase zoals die ten tijde van de eerdere SOVmaatregel werd toegepast. De abrupte overgang van een strikt gesloten setting naar een volledig extramurale plaatsing bij de ISD-maatregel kan volgens de Inspectie wel eens tot gevolg hebben dat er sprake is van grote aantal mislukkingen in de extramurale fase.

\section{Extramurale fase}

De tenuitvoerlegging van de laatste fase van de ISD-maatregel kan plaatsvinden buiten de inrichting. Het kan daarbij om opname in een GGz-kliniek gaan, maar ook om begeleide kamerbewoning of zelfstandige huisvesting in combinatie met een afgesproken dagbesteding. De Penitentiaire Maatregel (art. 44e en 44f) geeft aan dat de inrichting en het gemeentebestuur nadere afspraken maken over de tenuitvoerlegging van de extramurale fase, waarbij de gemeente uitvoeringsverantwoordelijk is.

Hoewel het intake- en het opnamebeleid van gemeenten en van zorginstellingen niet tot het toezichtdomein van de Inspectie behoren, is de 
beschikbaarheid van kwantitatief en kwalitatief voldoende zorgplaatsen wel essentieel voor een adequate invulling van de ISD-maatregel en daarmee voor het welslagen daarvan. Dat de extramurale plaatsingen zo moeizaam verlopen, leidt tot frustratie bij de ISD-ers die vaak lang op een plaats moeten wachten. Het grote aantal mislukkingen in de extramurale fase kan ook een gevolg zijn van het feit dat niet alle zorginstellingen waar ISD-ers worden geplaatst even goed zijn ingesteld op deze complexe doelgroep. Met uitzondering van de ISD-locatie Hoogvliet, is de reclassering op alle ISD-locaties stelselmatig belast met het toezicht op de extramuraal geplaatste ISD-ers. De manier waarop dit toezicht wordt ingevuld, wisselt echter. De ISD-maatregel wordt door de Inspectie omschreven als een bijzondere maatregel voor een bijzondere doelgroep. Het standaard sanctie- en terugplaatsingsbeleid zoals dat voor reguliere tot gevangenisstraf veroordeelden geldt, is hierop onvoldoende toegesneden. Er blijkt een grote behoefte te zijn aan maatwerk waarbij al naar gelang de omstandigheden een hernieuwde extramurale plaatsing sneller mogelijk is.

\section{Werkt de ISD?}

Om de werkzaamheid van de ISD-maatregel te kunnen aantonen is, zoals eerder vermeld, een effectevaluatie noodzakelijk. Deze zal naar verwachting in 2009 beginnen. ${ }^{13}$ In het voorgaande is ook duidelijk geworden dat de doelgroep complex is. Van de 228 zeer actieve veelplegers op de Twentse veelplegerslijst van 2008 staan 78 kandidaten voor de ISD, bij één van hen is de ISD-maatregel gevorderd, terwijl er 28 ISD-veroordeelden zijn. Dit betekent grofweg dat ruim een tiende van de zeer actieve veelplegers een ISD-maatregel opgelegd krijgt. Van deze Twentse ISD-ers zijn verder geen gedrags- en vaardigheidskenmerken beschikbaar, maar zij zullen voor het kunnen vaststellen van de werkzaamheid van de maatregel langdurig moeten worden gevolgd (ook geruime tijd na afloop van de maatregel). Bij het bevragen van de ISDers dient rekening te worden gehouden met hun cognitieve capaciteiten: niet alle meetinstrumenten zullen zonder meer kunnen worden afgenomen bij deze doelgroep.

13 INTRAVAL is momenteel in opdracht van het WODC van het ministerie van Justitie bezig met het in kaart brengen van de mogelijkheid tot het vormen van een controlegroep ten behoeve van de effectevaluatie. 
De onderzoeken die tot nog toe enig inzicht hebben gegeven in de werking van de ISD-maatregel geven vooralsnog geen hoopgevende verwachtingen. Voor een gedragsverandering is een gericht programma nodig. Dit is in ieder geval niet altijd en overal in de ISD beschikbaar. De beschikbaarheid van voldoende zorgplaatsen is eveneens essentieel voor een adequate invulling van de ISD-maatregel en daarmee voor het welslagen daarvan. Met name voor het onderste segment van de ISD-ers lijkt de hoop vooral te zijn gevestigd op de extramurale fase. De overgang van de intramurale naar de extramurale fase is in de praktijk echter groot, terwijl de instellingen waarop in de extramurale fase een beroep wordt gedaan niet altijd zijn toegerust op de doelgroep. Gemeenten lijken ook nog niet goed voorbereid op de komst van deze wat betreft zwaarte van de (deels psychiatrische) problematiek onderschatte doelgroep. De homogeniteit die kenmerkend was voor de SOV-doelgroep ontbreekt bij de ISD-populatie. De diversiteit van de doelgroep vereist een breed aanbod van voorzieningen binnen en buiten de penitentiaire inrichting, zodat ook de aansluiting op de nazorg beter kan verlopen. 